\title{
DAÑOS POR ACCIDENTE VEHICULAR EN CARRETERA CONCESIONADA RUTA 5 SUR TRAMO TALCA CHILLÁN
}

\author{
PUBLIC NUISANCE CAUSED BY A ROAD ACCIDENT ON THE \\ RUTA 5 SUR TALCA CHILLANN HIGHWAY
}

\author{
SENTENCIA DE LA CORTE DE APELACIONES DE SANTIAGO \\ DE 12 DE AGOSTO DE 2008
}

\section{MARCELO BARRIENTOS ZAMORANO*}

\begin{abstract}
RESUMEN: comentaremos un fallo de la Corte de Apelaciones de Santiago de 2008, que condena a una carretera concesionada a pagar una indemnización por daños a la familia sobreviviente de un conductor que resultó muerto, producto del choque de su automóvil con un ciclista y tres caballos al interior de una vía concesionada.

Palabras clave: carreteras; concesiones; daños.

ABSTRACT: we will analyze a Santiago's Appeal Court sentence, in a public nuisance on the highway, who resolving on the defendant a stricter form of liability. The case was about a road accident who envolved three horses and one cyclist too.
\end{abstract}

Key words: public nuisance; highway; liability

\section{INTRODUCCIÓN}

El caso que comentaremos es el de María Magali Canales Valenzuela y otros con Ruta 5 Sur Tramo Talca Chillán S.A. (2008): Corte de Apelaciones de Santiago 21 de agosto de 2008 (indemnización de perjuicios).

Imagine que usted va cómodamente manejando por una carretera concesionada, vías en las que se puede transitar a 120 kilómetros por hora por regla general, y de improviso aparece un hombre en bicicleta zigzagueando contra el tránsito llevando, además, atados a su precario medio de transporte tres caballos: simplemente surrealista ¿no le parece? Sin embargo, ello ocurrió en una carretera concesionada de nuestro país.

Más allá del cinematográfico hecho, digno de una película de Fellini, resulta también surrealista el abanico de posibilidades con que el ordenamiento chileno "soluciona" los daños que se causan en situaciones como estas dentro de una carretera concesionada. El espectro de posibilidades es tan amplio y las diferencias doctrinarias tan grandes, que bien

\footnotetext{
* Licenciado en Ciencias Jurídicas, Magíster en Derecho de la Empresa, Pontificia Universidad Católica de Chile, Doctor en Derecho con mención "Doctor Europeus", Universidad de Salamanca. Profesor de Derecho Civil de la Facultad de Derecho de la Pontificia Universidad Católica de Chile. Correo de contacto: mhbz@uc.cl
} 
merece la pena intentar dar una reseña, especialmente a los litigantes, sobre los posibles estatutos jurídicos de los que se puede echar mano por parte de quien resulte dañado en un accidente dentro de una carretera concesionada. Todo esto lo intentaremos a la luz de este inverosímil, pero real episodio, que se llevó por delante la vida del conductor del vehículo en cuestión, un padre de familia que dejó una cónyuge sobreviviente más tres hijos, y que tuvo el infortunio de encontrarse de frente con la furtiva incursión de un ciclista guiando tres caballares contra el tránsito en una vía concesionada.

\section{LAS NORMAS CHILENAS SOBRE RESPONSABILIDAD POR ACCIDENTES EN CARRETERAS CONCESIONADAS}

La responsabilidad indemnizatoria de la administración por daños derivados de insuficiencias en los caminos se desprende del artículo 174 inciso $5^{\circ}$ de la ley $\mathrm{n}^{\circ} 18.290$, de tránsito, al establecer que: "la municipalidad respectiva o el fisco, en su caso, serán responsables civilmente de los daños que se causaren con ocasión de un accidente que sea consecuencia del mal estado de las vías públicas o de su falta o inadecuada señalización. En este último caso, la demanda civil deberá interponerse ante el juez de letras en lo civil correspondiente y se tramitará de acuerdo a las normas del juicio sumario". Los problemas que presenta este artículo en su interpretación son, básicamente, el saber si nos encontramos con una presunción por falta de servicio o una responsabilidad legal objetiva. La doctrina se encuentra dividida al respecto.

No da igual el entender una u otra solución, lo que en todo caso debe suponer considerar las normas reglamentarias que rigen también esta materia. Ellas son el D.F.L. No 850, de 25 de febrero de 1998 (que fijó el texto refundido, coordinado y sistematizado de la Ley $\mathrm{N}^{\circ} 15.840$, de 1964, y el D.F.L. $\mathrm{N}^{\circ} 206$, de 1960). Este cuerpo de normas en su artículo $1^{\circ}$ dispone que: "el Ministerio de Obras Públicas es la Secretaría de Estado encargada del planeamiento, estudio, proyección, construcción, ampliación, reparación, conservación y explotación de obras públicas fiscales y el organismo coordinador de los planes de ejecución de las obras que realicen los servicios que lo constituyen y de las demás entidades a que se refieren los artículos $2^{\circ}$ y 30 de esta ley". Asimismo, el artículo 18 inciso $1^{\circ}$ añade que: "a la Dirección de Vialidad [que forma parte de la Dirección General de Obras Públicas, dependiente del Ministerio de Obras Públicas] corresponderá la realización del estudio, proyección, construcción, mejoramiento, defensa, reparación, conservación y señalización de los caminos, puentes rurales y sus obras complementarias que se ejecuten con fondos fiscales o con aporte del Estado y que no correspondan a otros Servicios de la Dirección General de Obras Públicas. La conservación y reparación de las obras entregadas en concesión, serán de cargo de los concesionarios". El artículo 87 agrega que: "Las obras públicas fiscales podrán ejecutarse, asimismo, mediante contrato adjudicado en licitación pública nacional o internacional...".

Por otro lado, ha de considerarse que la Ley $\mathrm{N}^{\circ} 18.290$, de Tránsito, expone en su artículo 100, que: "Será responsabilidad de las municipalidades la instalación y mantención de la señalización del tránsito, salvo cuando se trate de vias cuya instalación y mantención corresponda al Ministerio de Obras Públicas" (...) "En los caminos y calles que crucen a nivel 
una vía férrea, las empresas de ferrocarriles y el Ministerio de Obras Públicas o la municipalidad respectiva, en su caso, deberán colocar y mantener la señalización que determine el reglamento" (artículo 109) (...) "Las municipalidades y el Ministerio de Obras Públicas, según corresponda, serán responsables del buen funcionamiento de las señales luminosas" (artículo 112).

Las normas sobre responsabilidad indemnizatoria de las sociedades concesionarias, a su tiempo, tienen a lo menos seis fuentes que han de ser visitadas por cualquier litigante para poder encontrar fundamentos de responsabilidad en casos de accidentes que causen

daños en carreteras concesionadas, así:

a) D.F.L. 850 Ministerio de Obras Públicas, de 12 de septiembre de 1997, publicado el 25 de febrero de 1998, que fijó el texto refundido, coordinado y sistematizado de la Ley 15.840, de 1964, y D.F.L. 206, de 1960, cuyo artículo 87 autoriza al Ministerio de Obras Públicas (en adelante MOP) para ejecutar obras públicas mediante el sistema de concesiones.

b) El Decreto 900 MOP, de 31 de octubre de 1996, publicado en el Diario Oficial de 18 de diciembre de 1996, que fija el texto refundido, coordinado y sistematizado del D.F.L. MOP 164, de 1991 ("Ley de Concesiones de obras públicas").

c) Reglamento del D.F.L. MOP 164, de 1991, modificado por las Leyes 19.252 de 1993 y 19.460, de 1996, contenido en Decreto 956 del MOP de 6 de octubre de 1996, publicado en el Diario Oficial de 20 de marzo de 1999 ("Reglamento de la Ley de Concesiones de obras públicas").

d) Las respectivas Bases de Licitación de cada concesión (que se dividen en Bases administrativas, Bases técnicas y Bases económicas).

e) La Oferta Técnica y Económica, presentada por el adjudicatario de la concesión en la forma aprobada por el MOP.

f) Los Decretos Supremos de Adjudicación respectivos.

De acuerdo al Decreto No 900 MOP, de 1996, en su artículo 23: "El régimen jurídico durante la fase de explotación, será el siguiente. 1. El concesionario deberá conservar las obras, sus accesos, señalización y servicios en condiciones normales de utilización, y 2. La continuidad de la prestación del servicio le obligará, especialmente, a: a) Facilitarlo en condiciones de absoluta normalidad, suprimiendo las causas que originen molestias, incomodidades, inconvenientes o peligrosidad a los usuarios de las obras, salvo que la adopción de medidas que alteren la normalidad del servicio obedezcan a razones de seguridad o de urgente reparación, y b) Prestarlo ininterrumpidamente, salvo situaciones excepcionales, debidas a caso fortuito o fuerza mayor, cuyos efectos serán calificados por los contratantes, conviniendo las medidas que sean necesarias para lograr la más rápida y eficiente reanudación del servicio".

A su tiempo, el artículo 24 del mismo Decreto No 900 señala que: "El concesionario deberá velar por la perfecta aplicación de las normas y reglamentos sobre uso y conserva- 
ción de las obras concedidas". El artículo 35, del mismo cuerpo legal, expone que "El concesionario responderá de los daños, de cualquier naturaleza, que con motivo de la ejecución de la obra o de la explotación de la misma se ocasionaren a terceros, a menos que sean exclusivamente imputables a medidas impuestas por el Ministerio de Obras Públicas, después de haber sido adjudicado el contrato".

El reglamento de la Ley de Concesiones de obras públicas, dispone ciertas obligaciones en materia de seguros a las concesionarias, ya que el artículo 36 enuncia que:

"1. La sociedad concesionaria deberá tomar pólizas de seguro que cubran la responsabilidad civil por daños a terceros y los riesgos catastróficos que puedan ocurrir durante el periodo de concesión. Las sumas percibidas producto de los seguros por catástrofes serán destinadas a la reconstrucción de la obra, salvo que las partes acuerden destinarlas a otros fines u obras propias del contrato de concesión.

2. Las bases de licitación determinarán los plazos, forma, condiciones, modalidades y las demás cláusulas que deberán contener dichas pólizas, asi como el procedimiento de aprobación de estas.

3. Las bases de licitación podrán exigir otro tipo de pólizas de seguro".

El mismo reglamento de la Ley de Concesiones de obras públicas en su artículo 62, se preocupa de los daños a terceros, señalando que la sociedad concesionaria deberá adoptar durante la concesión, todas las medidas para evitar daños a terceros y al personal que trabaja en la obra. Igualmente, deberá tomar todas las precauciones para evitar daños a la propiedad de terceros y al medio ambiente durante la concesión de la obra. Agrega que la sociedad concesionaria será la única responsable de todo daño, de cualquier naturaleza, que con motivo de la ejecución de la obra y de su explotación se cause a terceros, al personal de la obra, a la propiedad de terceros o al medio ambiente, a menos que el daño sea exclusivamente imputable a medidas impuestas por el MOP después de la publicación del decreto supremo de adjudicación en el Diario Oficial.

El Artículo 63 del reglamento de la Ley de Concesiones de obras públicas se preocupa de fijar la Responsabilidad del concesionario, al señalar que: "El concesionario será siempre responsable del cumplimiento cabal, integro y oportuno del contrato de concesión, de la correcta ejecución de los proyectos y de las obras, y del cumplimiento de todas las obligaciones establecidas en el contrato de concesión, sin perjuicio de las funciones de dirección y control que corresponden al Ministerio de Obras Públicas".

Ante este cuadro legislativo, no es de extrañar que las soluciones sean amplias y variadas, pues para algunos existiría una responsabilidad indemnizatoria (legal) derivada directamente del artículo 35 de la Ley de Concesiones de obras públicas (Decreto $\mathrm{N}^{\circ}$ 900 MOP, de 1996). Para otros, una responsabilidad contractual de derecho común, ya que entre el usuario y la sociedad concesionaria concurriría un contrato de adhesión, que se perfecciona entre el usuario y la concesionaria al momento de pagar el peaje, de esta manera, la concesionaria resultaría obligada por el transcrito artículo 23 de la "Ley de Concesiones de obras públicas" (Decreto No 900 MOP, de 1996). También, hay quien estima que cabría una responsabilidad civil indemnizatoria derivada de una infracción a la Ley de Protección de los Derechos de los Consumidores: Ley 19.496. Como, asimismo, también podría pensarse en una responsabilidad civil extracontractual subjeti- 
va de derecho común, propia del título XXXV del libro IV del Código Civil, relativo a Delitos y Cuasidelitos civiles. Existen quienes consideran que en estos casos concurre la responsabilidad indemnizatoria por "falta de servicio", ya que de acuerdo al artículo 21 de la "Ley de Concesiones de obras públicas" (Decreto No 900 MOP, de 1996) "el concesionario cumplirá las funciones incorporadas en el contrato de concesión con arreglo a las normas del derecho público [...], por lo tanto, a las sociedades concesionarias ha de destinarse "la misma normativa que regula la actividad estatal y pública" 1.

Ante la "exuberante" legislación en la materia, y la consecuente multiplicidad de opiniones doctrinales que tratan de resolver esta espinuda cuestión, el fallo de la Corte de Apelaciones de Santiago 21 de agosto de 2008, se hace cargo de interesantes extremos que no dejan de llamar la atención de cara a la indemnización de los perjuicios, pasemos a revisarlos.

\section{PUNTOS DESTACADOS DEL FALLO}

A) Lucro cesante. Este fallo, lo que ya es una curiosidad por el escaso otorgamiento en general de esta partida, señala una cifra de indemnización del lucro cesante al considerarlo probado en autos, dando una fórmula de cálculo que ha sido desechada en otros fallos. Este mecanismo de cálculo, señala la sentencia, equivale: "a 168 ingresos mínimos mensuales que (...) se distribuirá entre cada uno de los demandantes, tomando en consideración el mismo criterio que el legislador emplea en el artículo 988 inciso segundo del Código Civil, por lo que corresponderá un $40 \%$ a su cónyuge sobreviviente, doña María Magali Canales Valenzuela, y un 20\% a cada uno de los hijos del causante: Camila Alejandra, Edwison Antonio y Ángela Marisol, todos de apellidos Palma Canales" 2.

B) Daño moral. La sentencia que comentamos considera que, en este caso, ha de tomarse en cuenta "el factor etáreo", por lo que duplica la suma total de indemnización de los hijos, en relación a la que otorga a la madre. No justifica la naturaleza de la indemnización por daño moral, ni las razones para estimar "el factor etáreo", lo que habría sido deseable ${ }^{3}$.

C) Reajustabilidad de las indemnizaciones. Este era un problema que tenía el fallo de primera instancia, ya que la sentenciadora ad quem no indicó cuáles montos eran entregados por daño emergente y cuáles por lucro cesante en su sentencia. Tampoco se pronunció en su momento sobre la reajustabilidad, cuestiones que se solucionan en la apelación, ya que "las cantidades se pagarán debidamente reajustadas de acuerdo a la variación que experimente el indice de precios al consumidor, más los intereses corrientes, que

\footnotetext{
1 SOTO Kloss (2001) pp. 187-210; Soto Kloss (2007) pp. 65-72.; Pierry ArRaU (2000) p. 39; Quintanilla PÉrez (2000) p. 50; KLenner (2007); RABat Celis (2007) pp. 279-298; Viñuela Hojas (2003) pp. 109-135; ViñUela HOJAS (2001), pp. 35-55; BARROS BOURIE (2006) pp. 1067-1071; ROMÁN Cordero (2007) p. 359; Diez SCHWERTER (2006) pp. 317-322 y Diez SCHWerter (2008) pp. 817 844 , entre otros.

${ }^{2}$ Considerando $5^{\circ}$ del fallo.

${ }^{3}$ Considerando $5^{\circ}$ del fallo.
} 
se calcularán a contar de la fecha en que quede ejecutoriada esta sentencia y la de su efectivo pago" 4 .

D) Responsabilidad objetiva de la concesionaria. El fallo de mayoría señala que ella concurre gracias a la normativa de las bases de la Licitación y en el Contrato de Concesión celebrado entre ella y el Fisco de Chile, normas explicitadas al inicio de este comentario de sentencia. No operaría la responsabilidad común del título XXXV del Libro IV del Código Civil, por cuanto es el concesionario quien "deberá tomar todas las precauciones para evitar daños a terceros". Además, "todo daño, de cualquier naturaleza, que con motivo de la ejecución de la obra y de su explotación se cause a terceros... será de exclusiva responsabilidad del concesionario...". Así, para la Corte de Apelaciones de Santiago, el legislador ha querido en estos casos que las normas supletorias del Código Civil, de aplicación general, y que regulan la responsabilidad extracontractual, no se apliquen. Sin embargo, con posterioridad no da más razones para sostener tal argumentación sino solamente la de "liberar al acreedor de la obligación de probar la culpa o dolo" 5.

El voto en contra en esta causa, señala en este punto, que la responsabilidad objetiva es más bien excepcional en nuestra legislación, y que " $n i$ los textos legales ni su correcto entendimiento pueden conducir a esta conclusión”. Sin embargo, no se explaya sobre las razones por las cuales afirma tal interpretación. Al menos en la doctrina comparada, la responsabilidad objetiva es absolutamente excepcional, tal y como señala acertadamente el voto en contra, ya que es efectivo que la responsabilidad objetiva no se ha impuesto sobre la responsabilidad por culpa en el Derecho civil: "El caso de Francia es paradigmático. Alli la responsabilidad objetiva de la administración existe hace más de un siglo por obra, sobre todo, de una jurisprudencia cuyas soluciones has sido importadas por buena parte de los países de su entorno" ${ }^{6}$. Es más, es inconcebible un sistema de responsabilidad civil sin límites cuantitativos de indemnización. En efecto, la responsabilidad civil estricta u objetiva es una excepción en nuestro ordenamiento civil, y en los casos en que el legislador la consagra en leyes especiales, de ordinario fija montos o límites de indemnización. Tal y como señala Barros, en los casos de responsabilidad en carreteras, más bien estamos ante una especie de culpa en la organización, que "no es una forma de responsabilidad estricta u objetiva, sino una manera de atender a los deberes de cuidado que el empresario tiene para con la victima, de acuerdo con los criterios generales de una responsabilidad fundada en la infracción de deberes de diligencia, solo que estos se refieren, en este caso, a la organización de recursos humanos, técnicos y físicos que el empresario pone en funcionamiento. Por eso, el defecto de conducta, que es característico de juicio relativo a la culpa y que surge de comparar el comportamiento efectivo con el estándar de conducta debida, es condición para dar por establecida, precisamente, una culpa en la organización". En este sentido, señala este autor, "el concepto que define el deber de servicio es la normalidad" 7 .

\footnotetext{
${ }^{4}$ Considerando $5^{\circ}$ del fallo.

5 Parte resolutiva del fallo.

${ }^{6}$ Mir (2002) pp. 199 y ss.

7 Barros (2006) pp. 189 y 746.
} 
E) Exposición imprudente al riesgo de la víctima. Por increíble que parezca, también se alegó por parte de la concesionaria en el actuar del conductor del vehículo (i!). Ha de recordarse que estamos ante el caso de un conductor que va tranquilamente por la vía concesionada y de improviso se le aparece un hombre en bicicleta zigzagueando contra el tránsito llevando, además, atados tres caballos. Cualquiera de nosotros que vaya por una carretera a 120 kilómetros por hora sabe o puede prever la posibilidad de chocar fortuitamente con un pájaro en vuelo rasante, pero imaginar encontrarse con tres caballos atados a un ciclista dudamos que sea algo a lo que un conductor, que además va correctamente por su vía en la carretera concesionada, se "exponga imprudentemente". Como señala el fallo de mayoría, este hecho es tan "original e inesperado (...) que no permite alertar suficientemente a un conductor como para impedir las consecuencias de ese actuar" 8 .

F) Aplicación de la buena fe. Este inefable concepto es también tenido en cuenta para señalar que el contrato de concesión obligaba a la concesionaria a instalar una barrera de protección al borde de la berma, ya que de acuerdo al artículo 1546 del Código Civil, es propio de la obligación de la concesionaria otorgar a los usuarios un servicio eficaz y seguro. Le asiste a la concesionaria una obligación de seguridad para con sus usuarios entonces. De esta manera, el fallo de mayoría señala que el daño no resulta tanto de encontrarse de frente con el ciclista que conducía los caballos, sino por la reticencia de la concesionaria, quien tenía la obligación de mantener el camino concesionado en términos tales de no producir daños a quienes por él transitan normalmente. Esta responsabilidad no puede desprenderse tampoco de la geografía del lugar o de la imposibilidad de construir medidas de protección, pues ello debió quedar señalado precisamente en el momento de celebración del contrato de concesión. Debe entenderse, a nuestro juicio, que tales imposibilidades geográficas deben quedar señaladas en las respectivas bases de licitación de cada concesión (que se dividen en bases administrativas, bases técnicas y bases económicas), la oferta técnica y económica presentada por el adjudicatario de la concesión en la forma aprobada por el MOP, y en los decretos supremos de adjudicación respectivos.

G) Los caballos fueron robados por el ciclista: argumento del voto en contra que desvirtuaría el nexo de causalidad. Cierta perplejidad despierta el voto en contra en este fallo. Señala que debe tenerse en cuenta que los animales le habían sido sustraídos a sus dueños y eran conducidos por la carretera en horas de la madrugada por una persona, presunto autor de los delitos, que se dio a la fuga. Este hecho, "de especial relevancia" a juicio del voto en contra, debió ser ponderado debidamente, puesto que sin su ocurrencia el accidente no se habría producido, y porque cabe preguntarse si preverlo "era una exigencia que pueda hacerse a la demandada". Nos preguntamos en qué habría cambiado el problema del daño y su relación causal con el hecho que lo causa, si los caballos hubieran sido de propiedad del ciclista que los guiaba. Ciertamente que en nada. No tiene importancia alguna, a nuestro juicio, en este caso la propiedad de los animales que causaron el daño en la carretera. Pertenecieran o no al ciclista los equinos, ¿cómo ingresaron a la carretera concesionada? ¿Es imputable a la carretera concesionada la

${ }^{8}$ Considerando $4^{\circ}$ del fallo. 
responsabilidad de no cumplir la obligación de seguridad para con los usuarios? Eliminando o suprimiendo mentalmente el hecho de que los caballos habían sido robados, igualmente el daño en la carretera se hubiera producido, por lo tanto, de poco importa en verdad su procedencia o el título por el que los guiaba el ciclista, sino más bien ¿cómo llegó hasta la vía concesionada un hombre en bicicleta, que se desplazaba contra el tránsito, y guiando al mismo tiempo tres caballos?

\section{BIBLIOGRAFÍA CITADA}

BARROS BOURIE, Enrique (2006): Tratado de responsabilidad extracontractual (Santiago, Editorial Jurídica de Chile) 1230 pp.

DiEZ SCHWERTER, José Luis (2005): "Notas sobre la acción preventiva de daños del artículo 2333 del Código Civil: a propósito de un fallo reciente", Revista de Derecho 217-218 (Concepción, Universidad de Concepción) pp. 317-322.

DiEZ SCHWERTER, José Luis (2008): "Reparación y Prevención de daños derivados de deficiencias viales en Chile: Panorama normativo y jurisprudencial” en Estudios de Derecho Civil III, 2007, Jornadas nacionales de Derecho Civil, (Valparaíso, 2007, Alejandro Guzmán Brito (editor científico), Editorial LegalPublishing) pp. 817-844.

KlenNer, Arturo (2007): Demanda de indemnización de perjuicios por daños personales o patrimoniales en el tránsito en vías concesionadas: una aproximación desde la práctica y la jurisprudencia (Santiago, Aremi) 326 pp.

Mir PuigPelat, Oriol (2002): La responsabilidad patrimonial de la administración (Madrid. Civitas) 374 pp.

Pierry ArraU, Pedro (2000): "La responsabilidad extra contractual del Estado por falta de Servicio", Revista de Derecho, volumen I (Santiago, Consejo de Defensa del Estado) pp. 39.

Quintanilla PÉREZ, Álvaro (2000): “¿Responsabilidad del Estado por actos lícitos?”, Revista de Derecho, volumen I (Santiago, Consejo de Defensa del Estado) p. 50.

Rabat Celis, Fernando José (2007): "Responsabilidad civil de las Sociedades Concesionarias de Obras Públicas Fiscales respecto del usuario de las mismas", en Estudios jurídicos en homenaje a los profesores Fernando Fueyo Laneri, Avelino León Hurtado, Francisco Merino Scheiling, Fernando Mujica Bezanilla, Hugo Rosende Subiabre (Santiago, Ediciones Universidad del Desarrollo) pp. 279-298

ROMÁN CORDERO, Cristián (2007): "La responsabilidad del Estado por los daños sufridos por el usuario de una carretera concesionada, por inactividad administrativa en ejercicio de sus facultades de inspección y vigilancia”, en FERNÁNDEZ RUIZ, Jorge y SANTIAgO SÁNCHEZ, Javier (coordinadores), Contencioso administrativo. Culturas y sistemas juridicos comparados (México, 2007), p. 359 Disponible en <http:// www.bibliojuridica.org/libros/5/2445/19.pdf>. [fecha de consulta: 08 de octubre de 2008].

SOTO KLOSS, Eduardo (2001): “Responsabilidad municipal por ausencia de señalización en la vía pública (Comentario a sentencia de la Corte Suprema de 13 de septiembre de 1999)", IusPublicum 6 (Santiago, Universidad Santo Tomás) pp. 187-210 
SOTO KlOSS, Eduardo (2007): "La responsabilidad de las municipalidades por los daños que produzca su inactividad/falta de servicio: principios básicos (notas para un recuento jurisprudencial)", en Ius Publicum 18 (Santiago, Universidad Santo Tomás) pp. 65-72.

Viñuela Hojas, Mauricio (2003): "La concesión de obras públicas en Chile: ¿Privatización de la responsabilidad del Estado en la empresa concesionaria?” Cuadernos de Extensión Jurídica 7 (Santiago, Universidad de los Andes) pp. 109-135.

ViÑuela Hojas, Mauricio (2001): "La responsabilidad por falta de servicio en el contexto del régimen de concesiones viales vigentes en Chile", Ius Publicum 7 (Santiago, Universidad San Tomás) pp. 35-55. 
